\title{
An Incomplete Congenital Septum of the Duodenal Bulb
}

\author{
Mehmet İbiş Engin Uçar Bülent Ödemiş Erkan Parlak \\ Department of Gastroenterology, Türkiye Yüksek Ihtisas Hospital, Ankara, Turkey
}

A 48-year-old woman presented at the outpatient clinic with a complaint of heartburn for the previous 2 weeks. Cardiologic evaluation revealed no cardiovascular reasons for these complaints. As she had not undergone gastroenterological evaluation previously, she was referred to our clinic. She had slight epigastric tenderness. Laboratory findings including complete blood count and biochemical assays were within normal limits. Abdominal ultrasonography was normal. Upper gastrointestinal endoscopy revealed antral gastritis and two separate continuations of the lumen after the pylorus while entering the bulbus. The rest of the duodenum was normal. Duodenoscopy showed that the bulbus was divided by a sep- tum (fig. 1). A guide wire was advanced through both openings, and this confirmed that only one continuation of the lumen was present (fig. 2). After clinical and endoscopic assessment, the patient was diagnosed as having an incomplete congenital septum of the duodenal bulb.

Acquired double pylorus occurs when peptic ulcer disease leads to the formation of a pyloroduodenal fistula in which the pylorus is divided by a septum. Acquired double pylorus is relatively more common than incomplete congenital septa of the duodenal bulb, and only three cases of the latter condition have been reported in the literature.
1

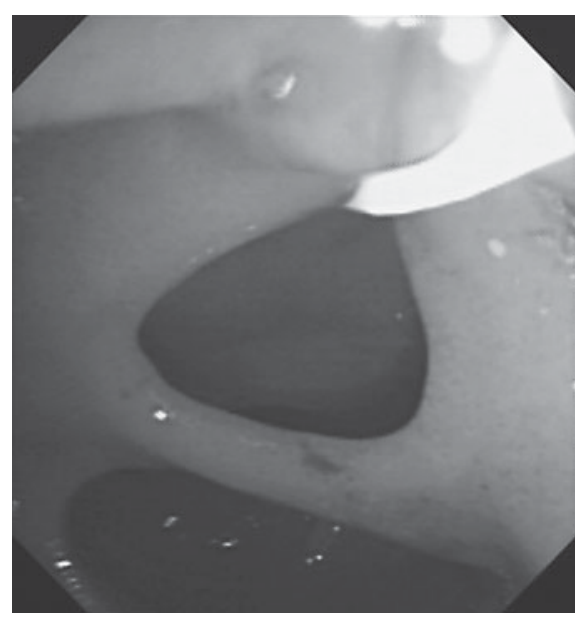

2

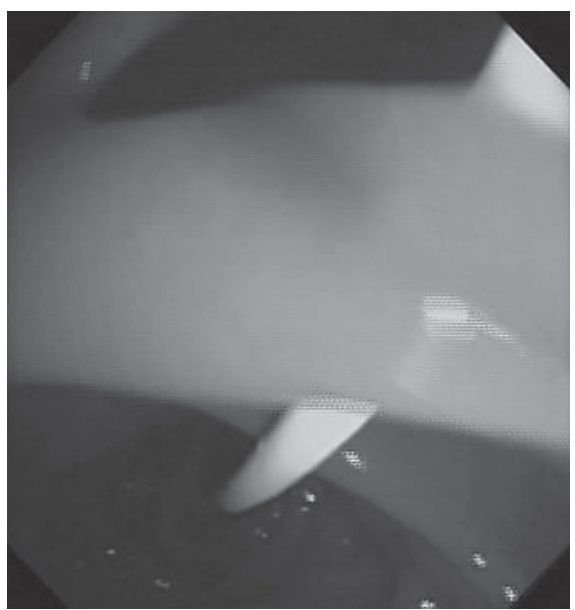

Fig. 1. Divided bulbus.

Fig. 2. A guide wire advanced through both openings.
E-Mail ibismehmet@yahoo.com 